At follow-up, cure rates were found to be $98 \%$ for A lumbricoides, $87 \%$ for $N$ americanus, and $47 \%$ for $T$ trichiura. Fecal egg count reduction showed similar declines in each species. The authors highlight the need for continued monitoring of treatment effectiveness in order to avoid resistance and maintain effective treatment. The poor efficacy against $T$ trichiura was thought to result from growing resistance, and the authors cited genetic markers in this species associated with resistance.

(PLoS Negl Trop Dis. 2011:5;e948) J Vercruysse, JM Behnke, M Albonico, et al.

Prepared by Anil Menon, MD, UTMB/NASA Aerospace Medicine Fellow, Galveston, TX, USA

\section{JOURNAL OF AMERICAN COLLEGE OF SURGEONS}

\section{Current Management of Copperhead Snakebite}

In this retrospective case review, the authors assessed the clinical outcome of copperhead snake (Agkistrodon contortrix) bites in order to determine the need for antivenom. They reviewed 142 bites that occurred between 1995 and 2010 at East Texas Medical Center. Data included an identification of the snake, age of the patient, presenting symptoms, laboratory analysis, length of stay, treatment rendered, and severity score as described by Dart and colleagues. ${ }^{1}$ Though 42 of the bites were unidentified, A contortrix bites were identified in 88 of the remaining bites. None presented with a grade 3 envenomation. Only $15 \%$ had a grade 2 envenomation. No antivenom was given and no deaths resulted from these bites. Though this study is limited by its size and retrospective design, the authors concluded that bites from copperhead snakes may require observation but are unlikely to require antivenom.
(ACS. 2011;212:470-474) JP Walker, RL Morrison.

Prepared by Anil Menon, MD, UTMB/NASA Aerospace Medicine Fellow, Galveston, TX, USA

\section{Reference}

1. Dart RC, Hurlbut KM, Garcia R, Boren J. Validation of a severity score for the assessment of crotalid snakebite. Ann Emerg Med. 1996:27;321-326.

\section{CLINICAL PEDIATRICS}

\section{Epidemiology and Profile of Pediatric Burns in a Large Referral Center}

This retrospective analysis evaluated burns at Children's Hospital of Michigan from 1998 to 2006. The authors analyzed admitted patients to their burn team. Annually, 200 patients are admitted and 1200 patients are treated as outpatients. Admission criteria included any 3rd degree burns, 2nd degree burns over $5 \%$ of total body surface area, lightning burns, circumferential burns, abuse-related burns, and burns to the face, hands, perineum, and joints. During this study, 2117 patients were admitted, with ages ranging from 0.1 to 19.7 years. Mean age was 5 years and the mode was 1.2 years. Forty percent of the burns happened in the kitchen (with $50 \%$ of those being scalds), and $7 \%$ of the burns were related to abuse (most likely occurring to victims less than 1 year old). The authors emphasize the importance of considering abuse when evaluating burns in children, and emphasizing cooking precautions to avoid burns in the kitchen.

(Clin Ped. 2011;50:391-5) A Shah, S Suresh, R Thomas, et al. Prepared by Anil Menon, MD, UTMB/NASA Aerospace Medicine Fellow, Galveston, TX, USA 